\title{
Therapeutic Potential of Hematopoietic Growth Factors for Treatment of Carbon Monoxide Neurotoxicity
}

Maryam Ghorbani ${ }^{1}$, Seyed Adel Moallem², Amir Hooshang Mohamadpour ${ }^{2}$ and Shabnam Shahsavand ${ }^{3 *}$

${ }^{1}$ Department of Pharmacology and Toxicology, School of Pharmacy, Baqiyatallah University of Medical Sciences, Tehran, Iran ${ }^{2}$ Department of Pharmacodynamics and Toxicology, School of Pharmacy, Mashhad University of Medical Sciences, Mashhad, Iran ${ }^{3}$ Department of Physiology and Pharmacology, School of Medicine, North Khorasan University of Medical Sciences, Bojnurd, Iran

Hematopoietic growth factors involved granulocyte-colony stimulating Factor (G-CSF) and erythropoietin (EPO) are cytokines involved in the regulation of normal hematopoiesis, influence stem cells survival, proliferation, and differentiation commitment $[1,2]$. These growth factors, significantly, have been considered in the management of many different neurodegenerative disorders with unknown definite treatment such as stroke [3,4], Alzheimer disease [5-7], Parkinson $[8,9]$. Both G-CSF and EPO have a noticeable role in central nervous system. Their special receptors are expressed in many regions of CNS and it is shown that they are upregulated in experimental models of stroke $[10,11]$. Several mechanisms are considered to describe the neuroprotective effects such as mobilization of hematopoietic stem cells to the injured regions $[12,13]$, differentiation of neuronal stem cells as well as neurogenesis, angiogenesis , anti-inflammatory [12,14,15], antiexcitotoxicity, antioxidant and anti-apoptotic effects $[2,10,16]$.

CO intoxication, a common cause of death especially during winter, induces cerebral hypoxia-ischaemia. It triggers neuropathological events include neutrophil degradation, enhancement and activation of myeloperoxidase, oxidative stress and lipid peroxidation, inflammation, apoptosis, demyelination and necrosis which may result in delayed neurological sequel $[17,18]$. There is no effective medication for managing neurological deficits following $\mathrm{CO}$ poisoning. It seems drugs or compounds which can inhibit any stages of neuropathological cascade, can exert a potential role in prevention and treatment of neurological outcome after CO exposure. G-CSF and EPO are shown to have robust neuroprotective properties. In recent experimental and clinical studies they could effectively promote neurological conditions after stroke. They recovered behavioral and histological impairments successfully $[19,20]$. In a recent study, CO intoxication proposed as a hypoxia induced neurotoxicity in a rat model. A single dose of G-CSF and EPO could attenuate CO neurotoxicity, alleviated histological changes such as neutrophil infiltration and neural necrosis which was shown by H\&E staining. It seems they inhibit neural apoptosis as well, since relative expression of activated caspase 3 decreases following treatments. G-CSF declines apoptotic cells showed by tunnel test. EPO significantly decreased myeloperoxidase (MPO) activity, a key biomarker of inflammation while G-CSF did not influenced MPO activity significantly. Regard to anti-inflammatory and anti-oxidant effects of these hematopoietic growth factors, they could successfully reduce edema and lipid peroxidation (MDA content) of the brain tissue. Both growth factors enhanced myelin basic protein (MBP) expression and remyelinated brain tissue which was impaired after poisoning. This was revealed after luxol fast blue (LFB) staining of brain tissue slices. After performing FPLC method on poisoned and treated brains it is was obvious that EPO regenerated MBP since the pattern of this protein renormalized. In order to affirm our data, the effect of G-CSF and EPO on serum levels of neurological biomarkers was investigated. Serum concentration of S100- $\beta$ and GFAP elevated after CO exposure. G-CSF and EPO significantly decreased these two biomarkers as a result of protective effect on astroglial cells [20-23]. According to obtained results it may be possible to deliberate hematopoietic growth factors as potential therapies for sever CO poisoning in clinical trial.

\section{References}

1. Demetri GD, Griffin JD (1991) Granulocyte colony-stimulating factor and its receptor. Blood 78: 2791-2808.

2. Juul S, Felderhoff-Mueser $U$ (2007) Epo and other hematopoietic factors Semin Fetal Neonatal Med 12: 250-258.

3. England TJ, Gibson CL, and Bath PMW (2009) Granulocyte-colony stimulating factor in experimental stroke and its effects on infarct size and functional outcome: A systematic review. Brain Res Rev 62:71-82.

4. Kumral A, Ozer E, Yilmaz O, Akhisaroglu M, Gokmen N, et al. (2003) Neuroprotective effect of erythropoietin on hypoxic-ischemic brain injury in neonatal rats. Biol Neonate 83: 224-228.

5. Ohyagi Y, Tabira T (1993) Effect of growth factors and cytokines on expression of amyloid beta protein precursor mRNAs in cultured neural cells. Brain Res Mol Brain Res 18: 127-132.

6. Tsai KJ, Tsai YC, Shen CK (2007) G-CSF rescues the memory impairment of animal models of Alzheimer's disease. J Exp Med 204: 1273-1280.

7. Lee ST, Chu K, Park JE, Jung KH, Jeon D, et al. (2012) Erythropoietin improves memory function with reducing endothelial dysfunction and amyloid-beta burden in Alzheimer's disease models. J Neurochem 120: 115-124.

8. Huang HY, Lin SZ, Kuo JS, Chen WF, Wang MJ (2007) G-CSF protects dopaminergic neurons from 6-OHDA-induced toxicity via the ERK pathway. Neurobiol Aging 28: 1258-1269.

9. Erbas O, Cinar BP, Solmaz V, Cavusoqlu T, Ates U (2015) The neuroprotective effect of erythropoietin on experimental Parkinson model in rats. Neuropeptides 49: $1-5$.

10. Marti HH1 (2004) Erythropoietin and the hypoxic brain. J Exp Biol 207: 32333242.

11. Schneider A, Krüger C, Steigleder T, Weber D, Pitzer C, Laage R, et al (2005) The hematopoietic factor G-CSF is a neuronal ligand that counteracts programmed cell death and drives neurogenesis. J Clin Invest 115: 2083-2098.

12. Noguchi CT, Asavaritikrai $P$, Teng R, Jia $Y$ (2007) Role of erythropoietin in the brain. Crit Rev Oncol Hematol 64: 159-171.

13. Paganessi LA, Walker AL, Tan LL, Holmes I, Rich E, et al. (2011) Effective mobilization of hematopoietic progenitor cells in G-CSF mobilization defective CD26-/- mice through AMD3100-induced disruption of the CXCL12-CXCR4 axis. Exp Hematol 39: 384-390.

14. Whalen MJ, Carlos TM, Wisniewski SR, Clark RS, Mellick JA, et al. (2000) Effect of neutropenia and granulocyte colony stimulating factor-induced neutrophilia on blood-brain barrier permeability and brain edema after traumatic brain injury in rats. Crit Care Med 28:3710-3717.

15. Agnello D, Bigini P, Villa P, Mennini T, Cerami A, et al. (2002) Erythropoietin

*Corresponding author: Shabnam Shahsavand, Department of Physiology and Pharmacology, School of Medicine, North Khorasan University of Medica Sciences, Bojnurd, Iran, Tel: 985832248805; E-mail: shabnamshahsavand@ gmail.com

Received January 25, 2016; Accepted February 08, 2016; Published February 12, 2016

Citation: Ghorbani M, Moallem SA, Mohamadpour AH, Shahsavand S (2016) Therapeutic Potential of Hematopoietic Growth Factors for Treatment of Carbon Monoxide Neurotoxicity. Med chem 6: 093-094. doi:10.4172/2161-0444.1000331

Copyright: ( 2016 Ghorbani M, et al. This is an open-access article distributed under the terms of the Creative Commons Attribution License, which permits unrestricted use, distribution, and reproduction in any medium, provided the original author and source are credited. 
Citation: Ghorbani M, Moallem SA, Mohamadpour AH, Shahsavand S (2016) Therapeutic Potential of Hematopoietic Growth Factors for Treatment of Carbon Monoxide Neurotoxicity. Med chem 6: 093-094. doi:10.4172/2161-0444.1000331

exerts an anti-inflammatory effect on the CNS in a model of experimental autoimmune encephalomyelitis. Brain Research 952: 128-134.

16. Kojima H, Otani A, Oishi A, Makiyama Y, Nakagawa S, et al. (2011) Granulocyte colony-stimulating factor attenuates oxidative stress-induced apoptosis in vascular endothelial cells and exhibits functional and morphologic protective effect in oxygen-induced retinopathy. Blood 117: 1091-1100.

17. Ginsberg MD (1985) Carbon monoxide intoxication: clinical features, neuropathology and mechanisms of injury. J Toxicol Clin Toxicol 23: 281-288.

18. Weaver LK1 (2009) Clinical practice. Carbon monoxide poisoning. N Engl J Med 360: 1217-1225.

19. Lanfranconi S, Locatelli F, Corti S, Candelise L, Comi GP, et al. (2011) Growth factors in ischemic stroke. J Cell Mol Med 15: 1645-1687.
20. Moallem SA, Mohamadpour AH, Abnous K, Sankian M, Sadeghnia HR, et al. (2015) Erythropoietin in the treatment of carbon monoxide neurotoxicity in rat Food Chem Toxicol 86: 56-64.

21. Ghorbani M, Moallem S, Abnous K, Tabatabaee Yazdi SA, Movassaghi AR, et al. (2013) The effect of granulocyte colony-stimulating factor administration on carbon monoxide neurotoxicity in rats. Drug Chem Toxicol 36: 102-108.

22. Ghorbani M, Mohammadpour AH, Abnous K, Movassaghi AR, Sarshoori JR, et al. (2015) G-CSF administration attenuates brain injury in rats following carbon monoxide poisoning via different mechanisms. Environ Toxicol.

23. Shahsavand S, Mohammadpour AH, Rezaee R, Behravan E, Sakhtianchi R, et al. (2012) Effect of Erythropoietin on Serum Brain-derived Biomarkers after Carbon Monoxide Poisoning in Rats. Iran J Basic Med Sci 15: 752-758. 